\title{
CONSELHOS LOCAIS DE SAÚDE: CAMINHOS E (DES)CAMINHOS DA PARTICIPAÇÃO SOCIAL
}

\author{
LOCAL HEALTH COUNCILS: PATHS AND (MIS)DIRECTION OF SOCIAL PARTICIPATION
}

CONSEJOS LOCALES DE SALUD: CAMINOS Y (DES)CAMINOS DE LA PARTICIPACIÓN SOCIAL

\author{
Edgar Andrade Lisboa ${ }^{1}$ \\ Francis Sodré ${ }^{2}$ \\ Maristela Dalbello Araújo ${ }^{3}$ \\ Bruna Ceruti Quintanilha ${ }^{4}$ \\ Sara Gonçalves Luiz ${ }^{5}$
}

Resumo Este estudo analisou a criação e a implantação dos conselhos locais de saúde no município de Anchieta, no estado do Espírito Santo. Buscou-se identificar os fatores que apoiaram ou limitaram a sua efetiva participação no contexto do Sistema Único de Saúde local. Por meio de abordagem qualitativa, realizaram-se 13 entrevistas com os conselheiros. Utilizou-se a análise de conteúdo, evidenciando três categorias trabalhadas neste texto: Ser ou não ser conselheiro de saúde? Eis a questão!; O não pertencimento e a não participação; e Conselhos locais de saúde: elos, meios e mediações. Concluiu-se que os conselheiros enfrentam grandes dificuldades que acabam por desvirtuar os caminhos desejados da participação social no âmbito do Sistema Único de Saúde. Por isso, é imprescindível que haja vontade política, apoio à participação efetiva e programas de educação para a cidadania dos atores envolvidos nesses fóruns, para que assim possam exercer de forma plena seu papel.

Palavras-chave Sistema Único de Saúde; participação social; conselhos de saúde.
Abstract This study examined the creation and implementation of local health councils in the municipality of Anchieta, state of Espírito Santo, Brasil. The goal was to identify the factors that supported or limited their effective participation in the context of the local Unified Health System. Using a qualitative approach, 13 interviews were carried out among the council members. Content analysis was used to show three categories worked on in this text: To be or not to be a health counselor? That is the question!; Non-belonging and non-participation; and local health Councils: links, means, and mediations. It was concluded that counselors face major difficulties that end up distorting the desired paths of social participation in the scope of the National Health System. Therefore, it is essential that there is political will, support for effective participation, and education programs for the citizenship of the actors involved in these forums so that they can exercise their roles to the fullest extent.

Keywords Unified Health System; social participation; health councils. 


\section{Introdução}

A análise da evolução histórica das políticas públicas de saúde no Brasil nos revela que, desde a década de 1990, intensificaram-se os processos de descentralização político-administrativa e de municipalização das políticas públicas, o que gerou transformações e fortaleceu as instituições democráticas no país. Foi nesse contexto que os conselhos e as conferências de saúde surgiram como importantes espaços políticos criados com o intuito de que a participação social assumisse um lugar estratégico na definição e execução das políticas de saúde (Correa, 2000; Bravo, 2001).

Contudo, apesar de inegáveis avanços ao longo da história, esses fóruns vêm enfrentando enormes desafios. Dentre eles, destacamos: a crise da democracia representativa e o risco de aprisionamento dos movimentos populares (Vianna, Cavalcanti e Cabral, 2009); a capacidade de intervenção dos usuários, mesmo com a paridade legalmente garantida (Guizardi e Pinheiro, 2006); e a apropriação dos conselhos pelo Poder Executivo, o que impossibilita o diálogo na construção e definição das políticas públicas de saúde (Longhi e Canton, 2011; Guizardi, 2009).

Diante das limitações dos canais tradicionais de articulação entre Estado e sociedade, outros espaços de participação social foram surgindo no país. Estes tinham como ideal a gestão participativa, no intuito de promover uma rede de participação social de alta capilaridade e investir na renovação e criação de instâncias mais flexíveis, porosas e efetivas às complexas demandas sociais. Instâncias nas quais os cidadãos em geral, independentemente de sua classe social, pudessem produzir uma nova compreensão sobre o papel do Estado - como sujeitos sociais, protagonistas na luta pela universalização dos direitos (Brasil, 2006). A ideia de gestão participativa foi disseminada com o fim de aumentar a participação direta da sociedade na gestão municipal, visando maior eficiência e efetividade das políticas públicas e buscando tornar a participação uma ferramenta de gestão pública (Brasil, 2006).

Dentre os vários casos de participação, surgiram os conselhos locais de saúde (CLSs) como alternativa flexível de participação social, mais porosos às demandas comunitárias. Tais conselhos tornaram-se componentes estratégicos da gestão participativa, por serem instâncias de participação mais próximas da comunidade - logo, mais próximas do cotidiano dos usuários e da dinâmica dos serviços de saúde. Assim, podiam interagir com outras organizações de bairro, como as associações de moradores, pescadores, trabalhadores rurais, dentre outras (Jacobi, 2002). Eram fóruns que podiam elaborar propostas para a política de saúde em sua localidade, levar sugestões ou reivindicações a instâncias superiores, como o conselho municipal de saúde, e também estabelecer relação entre conselheiros e a população, sendo uma forma de aumentar a mobilização, não afastando os representantes da sua base (Bravo, 2001). 
Nesse contexto, com base nas discussões do Grupo de Estudo em Trabalho e Saúde (Gemtes), do ingresso no Programa de Pós-Graduação em Saúde Coletiva da Universidade Federal do Espírito Santo e da experiência como profissionais de saúde, surgiu o interesse em estudarmos os conselhos locais de saúde. Neste artigo, abordamos a pesquisa realizada no município de Anchieta, no Espírito Santo (Lisboa, 2014).

Anchieta é um município a 73 quilômetros de Vitória e integra a Região Metropolitana Expandida Sul do Espírito Santo. Apresenta 417 quilômetros quadrados de extensão territorial e mantém-se como um município de pequeno porte populacional. De acordo com o Instituto Brasileiro de Geografia e Estatística (IBGE), censo 2010, o município possuía 23.902 habitantes, com 18.161 residentes na área urbana e 5.741 na zona rural (Brasil, 2010).

Se for analisado por sua composição territorial, Anchieta pode ser considerado predominantemente rural, pois suas propriedades rurais ocupam cerca de quarenta hectares de terra, ou seja, 93,5\% do território do município, com grande predomínio da agricultura familiar em $85 \%$ dessas propriedades (Instituto Futura, 2005). Entretanto, ao analisá-lo em relação à distribuição de seus habitantes, Anchieta é um município predominantemente urbano - ou seja, grandes propriedades de terras pertencendo a poucas pessoas (Brasil, 2010).

As principais atividades econômicas em Anchieta são indústria e serviços, pesca, agricultura, pecuária, turismo e comércio em geral. O município tem alta arrecadação de impostos da indústria siderúrgica e petróleo. Recebe muitos migrantes de outros municípios do Espírito Santo, inclusive da Região Metropolitana da Grande Vitória, atraídos pela especulação do crescimento e por oportunidades de empregos nas grandes empresas da região, que em sua maioria oferecem vínculos trabalhistas precários, como contratos temporários em empresas terceirizadas. Em Anchieta, as localidades do interior concentram aproximadamente $50 \%$ do eleitorado (Tomazelli, 2012).

Palco de grandes embates econômicos e ambientais, nos últimos anos essa região tem atraído muitas empresas e investimentos nas áreas de petróleo e siderurgia, 6 o que tem ocasionado um processo de metamorfose com profundas e rápidas transformações demográficas, econômicas e sociais (Rauta Martins e Rauta Ramos, 2012).

Anchieta tem nove territórios de saúde, cada um com uma unidade de saúde da família; logo, há uma cobertura de $100 \%$ da estratégia no município. Possui ainda uma rede de saúde composta por centro de especialidades unificadas (especialidades médicas, fonoaudiologia, fisioterapia, nutrição, dentre outras), centro de especialidades odontológicas, pronto atendimento, Centro de Atenção Psicossocial I (Caps I), Centro de Atenção Psicossocial Álcool e Drogas (Caps ad), Centro de Testagem e Aconselhamento, Centro 
de Controle de Zoonoses e Laboratório. Além desses serviços, o município tem convênio com um hospital filantrópico.

No que concerne aos CLSs de Anchieta, eles foram criados a partir de uma proposta de intervenção elaborada para um curso de especialização em atenção primária à saúde, ofertado e financiado pela Secretaria de Estado da Saúde do Espírito Santo em parceria com as secretarias municipais de Saúde e com instituições de ensino superior do estado (Carmo, 2012).

O referido curso de especialização foi criado com o intuito de capacitar os profissionais de nível superior que atuavam na atenção primária à saúde do estado e os gestores. Durante o ano de 2009, uma das turmas do curso, que era composta por gestores e profissionais de saúde de Anchieta, propôs a implantação dos CLSs como trabalho final do curso (Ferreira, 2012).

Assim, em 2010 os CLSs foram implantados. Realizaram-se eleições com participação dos cidadãos de cada um dos nove territórios de saúde do município para eleger os representantes dos usuários. Em relação aos profissionais, estes foram selecionados pela equipe de trabalhadores de cada unidade de saúde. Portanto, em cada território foram criados e implantados os referidos conselhos locais (Carmo, 2012; Ferreira, 2012).

A posse dos conselheiros eleitos ocorreu em um evento solene no auditório da Secretaria Municipal de Saúde, em que estiveram presentes representantes da sociedade civil, autoridades locais, gestores, conselheiros municipais de saúde e entidades de classe (Carmo, 2012; Ferreira, 2012). A partir das eleições, foram empossados em cada CLS do município seis conselheiros (três representantes dos usuários e três dos profissionais de saúde) e seus respectivos suplentes, totalizando 108 conselheiros em todo o município, com mandato de dois anos, podendo ser prorrogado por igual período, até a substituição por outros (Ferreira, 2012).

Cada conselho deveria então elaborar e aprovar seu regimento interno, com apoio do Conselho Municipal de Saúde, e reunir-se periodicamente, com reuniões ordinárias mensais e outras extraordinárias. Cumpria aos CLSs registrar tais encontros em atas pelos secretários eleitos dentro dos conselhos. No início, houve grande parceria dos conselhos com profissionais de saúde que cursavam a especialização em atenção primária à saúde, anteriormente citada (Ferreira, 2012).

Dentre as finalidades dos CLSs em Anchieta, encontra-se a de

possibilitar a participação organizada da população na administração dos serviços prestados, visando à melhoria da qualidade de vida e saúde da população, o que inclui a garantia do acesso universal e igualitário às ações e serviços necessários à promoção, preservação e recuperação de sua saúde (Anchieta, 2010).

Percebemos que a criação dos CLSs em Anchieta representou uma possibilidade de avanço na gestão participativa do Sistema Único de Saúde (SUS) 
local, acompanhando outras experiências no Brasil que demonstram o aumento da participação da sociedade nos processos decisórios que envolvem temas de interesse coletivo, como a saúde. Um desenvolvimento político que se consolida mediante a percepção de que os conselhos de saúde representam uma possibilidade de democratizar a gestão pública e aumentar a eficiência e a efetividade das políticas sociais (Ramos et al., 2012).

Diante desse quadro, propusemo-nos analisar o processo de criação e implantação dos CLSs em Anchieta, buscando identificar quais dificuldades e conquistas os referidos conselhos têm enfrentado desde que iniciaram suas atividades.

\section{Caminhada metodológica: uma abordagem qualitativa para interpretar os fenômenos sociais}

A pesquisa de campo teve início em abril de 2013, com contatos prévios com alguns informantes-chave nos nove territórios de saúde. Por meio desses contatos, verificamos que alguns conselhos foram pouco ativos desde sua criação e implantação, tanto que em 2012, dois anos após serem concebidos, a maioria $(65,6 \%)$ já não funcionava mais. Outros, porém, destacaram-se e mantiveram suas atividades até o referido ano $(33,4 \%)$.

Elegemos a abordagem qualitativa de pesquisa, por entendermos que a natureza desse problema de pesquisa exigia uma abordagem capaz de buscar interpretações dos fenômenos sociais, no sentido de analisar as vivências e experiências com base nas relações sociais (Minayo, 2008), possibilitando uma investigação do processo, não apenas dos resultados e do produto (Gaskell, 2002).

A coleta dos dados se fez por meio de entrevistas semiestruturadas. Os roteiros semiestruturados tinham questões "mais ou menos abertas" (Flick, 2004, p. 106). Nesse tipo de questão, "o entrevistador tem a possibilidade de discorrer sobre o tema em questão sem se prender à indagação formulada" (Minayo, 2007, p. 64). Alguns autores (Minayo, 2007; Gaskell, 2002; Simioni, Lefèvre e Bicudo Pereira, 1997) afirmam que as entrevistas são fundamentais para se obter informações sobre a realidade vivida pelo entrevistado.

De acordo com Flick (2004, p. 106), ao optar por realizar entrevistas semiestruturadas, "o entrevistador pode e deve decidir, durante a entrevista, quando e em que sequência fazer quais perguntas", pois se alguma resposta abarcar mais de uma pergunta, aquela questão já respondida pode ser descartada, para não se tornar repetitiva. Porém, essa atitude tem de ser tomada caso a caso (Flick, 2004).

As entrevistas tiveram como objetivo analisar o processo de criação e implantação dos CLSs e investigar como os referidos conselhos influenciaram 
(ou não) a política de saúde municipal. É importante destacar que as entrevistas foram realizadas de junho a setembro de 2013, período correspondente ao início de uma nova gestão municipal em Anchieta. Nas eleições ocorridas no final de 2012, após oito anos de mandato, o antigo prefeito não conseguiu eleger sua indicação ao cargo, dando lugar ao candidato da oposição partidária. Ressaltamos que a criação e a implementação dos CLSs ocorreram justamente durante o mandato da gestão que não se manteve no poder.

A seleção dos conselhos para o estudo buscou duas experiências distintas no município: uma constituída de um conselho mais atuante, cujos conselheiros reuniam-se regularmente desde sua criação; e outra cujo conselho não se manteve ativo desde o princípio. O conselho mais atuante pertencia a uma unidade de saúde que tem por território de abrangência três comunidades do município, formadas por moradores mais antigos e por poucas pessoas com contrato de trabalho temporário, o que mostra baixa transitoriedade da população. As referidas comunidades eram territorialmente próximas ao serviço de saúde, local em que ocorriam as reuniões do CLS, e tinham fácil acesso ao transporte urbano.

O outro conselho pertencia a uma unidade de saúde referência de cinco comunidades do município de formação mais recente, portanto com moradores mais novos, além de terem se mudado em razão do trabalho nas empresas locais. Muitos tinham vínculos temporários de emprego, o que promovia uma rotatividade grande de moradores, porque ao término dos contratos costumavam se mudar para uma localidade mais próxima do novo local de trabalho. Nessas comunidades, o território geográfico é grande, o que as tornava distantes do serviço de saúde. Sem contar que havia pouco acesso aos serviços de transporte urbano.

O intuito da seleção de tais conselhos foi identificar diferenças no processo de desenvolvimento desses espaços, capazes de colaborar com o êxito ou não deles. Percebemos que a dificuldade de acessar os espaços em que ocorriam as reuniões do CLS e a existência de grande transitoriedade de moradia na comunidade interferiram no envolvimento da população com os conselhos. Desse modo, quando o acesso era mais fácil às unidades de saúde e a população morava de forma mais fixa e por mais tempo no local, o CLS progrediu. Apesar disso, tanto no conselho que obteve êxito como no que se dissolveu, notamos nas entrevistas convergência nas falas no que se referia ao que se constituía como apoio ou entrave para o desenvolvimento do conselho local.

Entrevistamos 13 conselheiros de saúde. Para a escolha deles, procedeu-se a uma seleção levando em consideração os seguintes critérios: ter sido eleito ou selecionado como conselheiro a partir da criação dos conselhos locais, em 2010; as entrevistas seriam prioritariamente com os conselheiros titulares com suplentes, só nos casos em que não foi possível entrevistar o titular. 
Dos conselheiros entrevistados, sete eram representantes dos usuários e seis dos profissionais.

A confidencialidade dos dados foi assegurada, e com o intuito de garantir o anonimato dos pesquisados, suas respectivas falas foram identificadas no decorrer deste artigo por siglas, com uma abreviação do termo conselheiro (C) seguida de um número.

Os dados provenientes das entrevistas realizadas foram explorados seguindo a proposta de análise de conteúdo de Bardin (2000). Assim, emergiram três categorias: Ser ou não ser conselheiro de saúde? Eis a questão!; O não pertencimento e a não participação; e Conselhos locais de saúde: elos, meios e mediações.

Para iniciar a pesquisa de campo, foi requerida autorização prévia à Secretaria Municipal de Saúde de Anchieta e ao Comitê de Ética em Pesquisa da Universidade Federal do Espírito Santo (CEP/Ufes). Foram atendidas, assim, todas as prerrogativas da resolução n. 466/2012 do Conselho Nacional de Saúde para Pesquisa Científica em Seres Humanos (Brasil, 2012). A pesquisa foi aprovada tanto pela Secretaria como pelo CEP/Ufes.

\section{Os conselhos influenciaram ou não a política municipal de saúde?}

Os CLSs foram criados com o intuito de ser mais um espaço de negociação, democracia e participação social, aproximando a comunidade da gestão do SUS local. Todavia, percebemos que os conselheiros enfrentavam dificuldades que destoavam dos objetivos da participação social no âmbito do SUS, o que comprometia a efetivação desses espaços no município em estudo.

\section{Ser ou não ser conselheiro de saúde? Eis a questão!}

Durante a pesquisa, foram notórias, entre os conselheiros entrevistados, dúvidas e incertezas quanto ao exercício de seu papel. Como os CLSs foram implantados a partir da iniciativa da gestão municipal, os conselheiros eleitos ou indicados (no caso dos representantes dos profissionais de saúde) aguardaram por capacitações, reuniões organizadas pela gestão, apoio e explicações de suas funções, de como seriam organizados os conselhos e como as ações seriam desenvolvidas. Mas o que detectamos é que pouco ou quase nada disso ocorreu - o que contribuiu, segundo os entrevistados, para aumentar as incertezas em relação à prática como conselheiro de saúde.

Os conselheiros sem treinamento, pedindo para entender qual era o papel, e não teve reunião (...) os conselheiros perdidos (...) a gente reunia, mas não sabia ao certo o que falar, que pauta ter. E ninguém se importava (C6). 
Ser conselheiro local, vivenciar as dificuldades da comunidade e as crises da política local e ainda ter a oportunidade de vocalizar os interesses da comunidade: tudo isso foi considerado pelos entrevistados como uma grande oportunidade de participação e como fatores potenciais para o desenvolvimento de um conselheiro local de saúde. Um 'bom conselheiro' foi apontado por eles como aquele que era ativo, líder na comunidade, participativo nas atividades das unidades de saúde e no território, envolvido, interessado e, acima de tudo, um sujeito político ciente dos seus direitos e determinado a lutar por eles.

Os conselheiros de saúde afirmaram, no entanto, ter a sensação de estarem despreparados para exercerem essa função. Assim, mesmo que se mostrassem ativos, uma vez que relataram reunir-se para construir sua prática, muitas foram as falas que remetiam a uma insegurança em exercer o papel de conselheiro. Eles afirmaram que faltava conhecimento teórico e organizacional. Sobre sua função, foram comuns afirmações como: "A gente tá aí, entendendo que é buscar sugestões, melhorias. Mas, na verdade, ninguém falou pra gente" (C6).

Acreditamos que a formação do conselheiro se faz, então, como uma ferramenta importante. Entendemos que ela pode colaborar com a defesa dos interesses da comunidade em relação à política de saúde, construindo assim uma nova cultura política, mais democrática e capaz de gerar transformações nos níveis de saúde e nos modos de vida das populações (Bispo Júnior e Martins, 2012) - e não como uma formação teórica, pautada apenas no repasse de informações sobre as leis que regem o SUS ou dos conteúdos necessários para o exercício da atribuição (Cotta et al., 2011).

A educação permanente (EP) para o controle social do SUS mostra-se como importante ferramenta para esse processo (Luiz, Quintanilha e Dalbello-Araújo, 2014). A formação de conselheiros de saúde pautada nos princípios da EP é caracterizada por lhes proporcionar formação e mobilização, de forma articulada e interdependente, numa perspectiva de produção coletiva de saúde. Assim, a EP é apontada como estratégia capaz de promover o protagonismo dos atores locais, o que os levará a um processo contínuo e progressivo de reflexão e transformação de suas práticas pessoais e institucionais (Brasil, 2007).

Eu acredito muito no controle social (...) é a voz da comunidade dentro da secretaria (...). Eu fico às vezes assim desanimada, mas ao mesmo tempo eu penso que se eu deixar de fazer isso, eu estou deixando de exercer minha cidadania, e a lei me permite isso. É uma forma da gente se colocar, e não deve desanimar, não. Tem que continuar lutando $(\mathrm{Cl})$.

Ser ou não ser conselheiro de saúde? Questionamento que permanecia em cada sujeito entrevistado, uma vez que ao mesmo tempo que todos tinham 
o desejo de promover mudanças nas políticas de saúde local e municipal, enfrentavam o desafio de estarem envoltos na insegurança de exercer um papel instituído.

\section{O não pertencimento e a não participação}

Um dado que chamou a nossa atenção foram os relatos dos entrevistados de que a comunidade pouco conhecia sobre os CLSs existentes no município. Foi recorrente fazerem essa afirmação durante a entrevista. Relataram ainda que muitos usuários apenas participaram das eleições e não recorriam mais aos CLSs como um espaço de participação, denúncia ou contestação: “Ninguém falou nada mais, ninguém nem se lembra disso [os conselhos] mais. Foi uma coisa que passou bem em branco aqui na comunidade" (C10).

Um estudo realizado em 2011 identificou que pouco mais de $5 \%$ dos usuários da Estratégia Saúde da Família tinham conhecimento da existência dos conselhos de saúde (Martins et al., 2011). Quando a população não se apropria dos canais legalmente instituídos de participação no SUS, seu desempenho pode tornar-se limitado devido à frágil capacidade de se promoverem articulações com outros segmentos populares e sociais, perdendo-se assim o sentido desse fórum (Martins et al., 2008).

Acreditamos que o fato de a população de Anchieta não se envolver no processo de criação, implementação e desenvolvimento dos CLSs relaciona-se ao sentimento de não pertencimento a esses fóruns. Isso é consequência do processo de formação dos referidos conselhos, da descrença da população em relação à política local e da chegada de muitos migrantes à região, em razão das novas empresas instaladas no município.

Os conselhos locais de saúde de Anchieta foram criados e instituídos via processo institucional, exógeno à comunidade - porque foram fruto de um projeto de final de curso composto por profissionais de saúde e gestores. Portanto, não houve envolvimento da população para discutir viabilidade e importância da instituição desses conselhos.

Os conselheiros também deixaram claro em suas falas que a comunidade era descrente em relação ao Estado como provedor de direitos legalmente garantidos - como explicitado a seguir:

As pessoas não levaram a sério (...). Quando a gente fala sobre esta questão de público, as pessoas já começam a deixar a desejar. As pessoas falam: "Ah, isso não vai ser levado a sério, a Prefeitura não vai fazer questão" (C9).

De acordo com Farias (2011), a democracia representativa enfrenta, nos últimos tempos, intensa crise por ser centralizadora, burocratizada e 'elitizada'. 
Com isso, a população sente-se não ouvida, não participante das decisões, da política, do emprego dos recursos públicos. Deparamo-nos com numerosos sujeitos que se sentiam não representados, e consequentemente não reconheciam o conselho como espaço para participação social. Vale ressaltar que essa percepção esteve presente tanto nos conselheiros participantes do CLS que consideramos mais atuante como naqueles cujas atividades foram interrompidas.

A comunidade não tem essa noção de conselho. Se nós que estamos dentro como conselheiros não temos essa noção, a comunidade, então... (C6).

A população não recorre, não. Ou eles vêm aqui no posto reclamar ou vão diretamente à secretaria (C5).

Outro relato que chamou a atenção no que corresponde ao não reconhecimento dos CLSs foi a dificuldade da comunidade em se envolver nas lutas coletivas, em detrimento de conquistas individuais e clientelistas.

Eles não estão habituados, acostumados com esse tipo de organização (...) se você disser que vai fazer para mim, você se dá bem, mas se prometer para a coletividade, o que deveria ser o certo, aqui não é bem visto. Então como não podemos oferecer no conselho nada individual, pessoal, de favor, as pessoas não se interessam (C4).

Um estudo realizado no município de Vitória da Conquista, no estado da Bahia, também detectou um misto de individualismo e imediatismo nas comunidades, pois as pessoas só demonstravam interesse em se envolver no conselho de saúde em questões que lhes garantissem benefícios pessoais diretos e imediatos, como se tornarem conhecidas dos profissionais da unidade e assim terem acesso facilitado aos serviços de saúde, conseguindo marcar consultas e exames com maior facilidade (Bispo Júnior e Martins, 2012). Envolver-se no conselho de saúde apenas em questões que garantam benefícios pessoais vai de encontro ao projeto de funcionamento desses conselhos, os quais devem ser engajados em lutas coletivas.

O município de Anchieta, por ser predominantemente rural, apresenta ainda mais um fato para o sentimento de não pertencimento em relação aos CLSs: as pessoas não vivenciarem muito a realidade política.

Nos interiores as pessoas trabalham mais lá na sua hortinha, no seu terreno, e isso muitas das vezes deixa as pessoas fora da realidade (...) o interior tem vivenciado pouco essa realidade de política, conselho, discussões, tanto da saúde quanto da educação (C12). 
Lá a gente vive isolado. Não tem nada, ninguém dá ideia pra nada, e os políticos só vão lá na época de eleição pra pegar votos. Acabou a eleição, você não tem ninguém nunca mais. Pra mais nada, nem pra ver se está precisando de alguma coisa, nada (C9).

O meio rural é apresentado pelos entrevistados como uma realidade bem distante da velocidade e do turbilhão de movimentos que geralmente povoam o âmbito urbano. A sensação de viver isolado, esquecido e ainda de ser meramente usado pelo sistema desenvolvido nas cidades - que garante o direito ao voto, apenas - não corresponde às expectativas e às reais necessidades dessa população. A maioria das questões relacionadas aos movimentos democráticos, às disputas políticas, à busca pelo desenvolvimento que estão presentes no meio urbano, ainda não alcançou com êxito o meio rural. Com exceção dos movimentos populares envolvidos na luta pela reforma agrária ou pela proteção ambiental, pouco se conhece no Brasil a respeito de organizações ou grupos envolvidos em movimentos populares e democráticos no meio rural.

É muito comum nas comunidades tradicionais do interior a existência de uma forma peculiar de vida, a seu modo, fazendo uso da terra, cuidando das criações, usufruindo da natureza e estabelecendo relações com ela - em geral, sujeitos que têm consciência de si e dos que estão a seu redor. Assim vivem dia após dia se envolvendo em suas ações a partir de suas práticas, de seus saberes e de sua relação com o meio (Rauta Martins e Rauta Ramos, 2012).

Dessa maneira, tudo que é inserido de diferente da rotina já estabelecida acaba visto como gerador de tensão, de conflito com o modo de vida ali estabelecido - porque vem incorporado de formas de viver, agir e pensar que desqualificam as práticas e saberes já existentes ali, por meio de uma apropriação dos espaços de reprodução da vida social (Rauta Martins e Rauta Ramos, 2012). Nossa hipótese é de que foi dessa forma que os CLSs foram percebidos pelas comunidades rurais do município de Anchieta, que, oprimidas pelo abandono do poder público, não viram nesses espaços nenhuma esperança de melhoria da sua realidade já estabelecida.

Eu mesmo não falei, mas lá no fundo eu pensava assim, que isso não ia dar em nada. Isso porque lá na minha comunidade todo mundo já está desacreditado, entendeu? Lá não tem nada, nunca ninguém ligou pra gente, então era mais uma propaganda enganosa, vamos dizer assim (C9).

Outro fator que produziu nos conselheiros e na comunidade o sentimento de não pertencimento em relação aos CLSs foi a instalação das multinacionais no município. Com a chegada delas, grande extensão territorial passaria a ser ocupada, consequentemente ocasionando o deslocamento de boa parte dos moradores para outro lugar da cidade. 
Então, as pessoas dizem (...) 'Ah, por que eu vou me envolver, querer melhorar alguma coisa, porque eu não vou ficar aqui mesmo, e vai vir uma máquina e vai retirar tudo' (C9).

E a gente ouvia (...) 'Ah, eu não vou fazer isso ou aquilo porque a empresa está vindo'. Então, até a gestão ficava dizendo 'pra que fazer unidade nova? (...) pra que fazer o asfalto?' (C10).

Devido à instalação das multinacionais, o município começou a receber muitos migrantes, que formavam comunidades. Eles chegavam ao município em busca de emprego, e mesmo tornando-se moradores continuavam a se considerar estrangeiros ou migrantes ali.

Assim, para essas comunidades, ter um CLS criado e instituído também não fazia sentido, pois não se sentiam pertencentes a ele, na medida em que ainda não se sentiam pertencentes ao território que hoje ocupam, pois tinham uma noção de transitoriedade. Mais uma vez, não há lugar nesse plano para lutas coletivas. Cada um, cada família luta pelo que é seu: pela sua vida, pelo seu sustento, até mesmo pela sua saúde ou contra a ausência dela.

Deparamo-nos, portanto, com conflitos que derivam das relações entre o capital, o trabalho, o desenvolvimento e a subsistência do ser humano. Conflitos que se envolvem e interferem diretamente na identidade social desses sujeitos, que é concebida como socialmente construída, tanto por suas relações com o ambiente físico onde as pessoas estão inseridas (o ecossistema) quanto pela sua relação com o todo que o cerca (a sociedade) (Moreira, 2006).

Assim, com uma identidade social conflituosa, a participação social torna-se comprometida, pois para que esta ocorra se depende, dentre outras coisas, da cultura política local e do grau de envolvimento e mobilização social (Côrtes, 2010). Nesse sentido, observamos que simplesmente institucionalizar um espaço de participação social como os CLSs não é suficiente para se promover a mobilização social e o envolvimento comunitário.

\section{Conselhos locais de saúde: elos, meios e mediações}

Outra categoria que emergiu dos dados coletados em entrevista foi a compreensão de que o funcionamento e o desenvolvimento dos CLSs estão diretamente associados ao estabelecimento de elos com outras instâncias como as associações de moradores, os órgãos públicos de defesa e proteção ao cidadão, o conselho municipal de saúde e, principalmente, a gestão municipal. Na ausência desses elos, os CLSs se tornam limitados ao exercer seu papel de mediador entre comunidade e gestão municipal. 
O conselho não avança mais, não devido a nossa participação, não, mas por força política. Ele precisa de mais, precisa ter respaldo do conselho municipal, do gestor, de tudo, para ele se ver com força. E nós não tivemos até hoje (C3).

(...) se dependesse só daqui, de nós, seria mais atuante, mas tem muita gente por trás. Não depende só de nós. Se dependesse só de mim, dos outros, mas nós temos que recorrer a alguém mais, né? (C7).

Essa percepção mostra que realmente os CLSs têm limites em sua capacidade de ação, por isso torna-se tão importante a articulação com outras instâncias de poder e gestão pública (Cruz et al., 2012). Entretanto, o que observamos é que nesse meio de relações e conflitos o descaso das possíveis parcerias estabelecidas, a falta de apoio e incentivo e a sensação de abandono por parte da gestão foram apontados como fatores convergentes para desânimo, impotência e apatia ante o desenvolvimento dos CLSs.

Eu acho que esta ferramenta, o conselho local, é muito importante para o controle social, para a gente (...) solicitar as coisas que a gente precisa (...) eu sinto que a gente pode fazer muito mais, que é importante e que tem que ser valorizado. E a gente precisa dar força para que não entre na rotina do deixa pra lá, do esquecimento $(\mathrm{Cl})$.

(...) eu percebi que perdeu um pouco o elo. As pessoas não se juntavam mais para saber quais eram as necessidades da comunidade, se está precisando disso, vamos correr atrás. Não! As pessoas sempre esperaram da parte administrativa. Perdeu um pouco o elo (C9).

Os conselheiros percebiam a necessidade de estabelecerem os elos e insistiam em tal aspecto para o alcance dos objetivos nesses fóruns.

Acho que a gente só não tem muita força. Depende deles, né? Não tem muito que fazer. Pede determinado assunto que a gente não tem poder. A gente tenta fazer e não consegue. Injustiça. Faz reunião e não consegue (C5).

Diante desse quadro, questionamos onde estaria a partilha de poder, essencial nos discursos e práticas democráticas, quando o que vimos na realidade foi uma correlação de forças que os impediam de influenciar a política de saúde local, municipal, e que dificultava as repercussões desejadas por esses sujeitos políticos. Relembramos que não era essa a finalidade dos CLSs, uma vez que foram criados para "possibilitar a participação organizada da população na administração dos serviços prestados, visando à melhoria 
da qualidade de vida e saúde da população" (Anchieta, 2010). Um discurso retórico que não alcançou a prática das vivências, das reais necessidades da comunidade.

Ainda nesse intuito de alcançar os objetivos propostos e estabelecer elos, surgiu no ideário dos conselheiros locais a possibilidade de parceria com o conselho municipal de saúde de Anchieta. Na concepção dos conselheiros locais, o conselho municipal deveria ser um apoio à implantação e desenvolvimento dos CLSs, ajudando na construção de seus regimentos internos, no enfrentamento de dificuldades, no esclarecimento de dúvidas, na mediação junto à gestão. Houve muitas expectativas e também muitos desapontamentos com o conselho municipal, pois mesmo presentes nas reuniões, os conselheiros locais não conseguiam incluir suas demandas nas discussões desse conselho, que deveria agir no sentido de acolher e apoiar tais comunidades.

Aí a gente levava as nossas sugestões para o conselho municipal, para que o conselho municipal comprasse a nossa briga, entendeu? (...) Mas não conseguimos colocar assuntos na pauta (C6).

Às vezes, a gente quer avançar, e quando chega lá, por outras questões que eles têm que resolver, deixam as questões da gente em segundo plano (...) eles falam da boca pra fora, não é de todo interesse que o conselho local esteja fortalecido. É um descaso (...) falta de interesse mesmo (C3).

Vianna, Cavalcanti e Cabral (2009) identificaram tais dificuldades no âmbito dos conselhos municipais de saúde. Apontaram, por exemplo, a imensa pauta de problemas gerais comuns em reuniões, que por não serem organizados por grau de prioridade, não são resolvidos nem mesmo reapresentados.

Nesse sentido, o que nos perguntamos é o que tem ocupado demasiadamente tais pautas de reuniões. Seriam demandas de outras comunidades? Projetos para melhorar o acesso, a assistência e os serviços? Semelhante a isso, Soratto, Witt e Faria (2010) verificaram, por exemplo, que durante reuniões e encontros entre profissionais de saúde, gestores e população, as informações que na realidade são repassadas e os assuntos discutidos são de caráter eminentemente técnico e normatizador.

Longhi e Canton (2011) criticam ainda o fato de que em alguns casos a participação social nesses fóruns tem se limitado apenas à aprovação de programas ou pacotes ministeriais de financiamento para a saúde, que muitas vezes não condizem com as reais reivindicações que, historicamente, representam bandeiras de luta dos militantes em saúde.

Uma pesquisa encomendada pela Controladoria Geral da União, em 2006, indicou que os conselhos municipais, além de não influenciarem efetivamente 
a elaboração de políticas sociais, conforme esperado, foram em sua maioria cooptados e aparelhados pela gestão, o que podemos chamar de 'prefeiturização'. Trata-se de um controle que legitima ações e medidas questionáveis tanto do ponto de vista técnico e administrativo quanto do de sua natureza ética e política, pois pode transformar tais espaços em verdadeiros instrumentos para encobrir fraudes do sistema político ou privilegiar as classes dominantes (Lyra, 2007). E o que é ainda mais cruel: tudo na ótica camuflada de que todas as coisas são realizadas com a ciência e aprovação da população.

A partir dessa cooptação, a noção de controlar o Estado se reverte em controle do Estado sobre um fórum institucionalizado para participação da população na gestão das políticas públicas. É o que Demo (1995) considera 'cidadania tutelada', uma concessão vinda de cima, do Estado, que por reproduzir a pobreza política das maiorias não abre espaço à consciência crítica necessária para acabar com essa tutela que impede o protagonismo de sujeitos políticos em busca da democracia. Um Estado que é exógeno, distante no ideário da comunidade, e que para ser alcançado são necessárias tentativas de acesso mediadoras, criadas a partir dessas instâncias institucionalizadas ou não.

\section{Considerações finais}

Os CLSs são entendidos como uma das alternativas de ordenamento da estrutura organizacional do sistema de saúde. Eles dão à participação social um papel estratégico na definição e na execução das políticas de saúde. Percebemos que existem inegáveis avanços alcançados ao longo dos anos por parte da institucionalização da participação social nos conselhos; contudo, ainda se enfrentam muitas limitações.

Neste estudo, demos enfoque à atuação de CLSs em um município no interior do Espírito Santo. Entendemos que tais instâncias, por serem formadas em cada unidade de saúde existente no município, se tornam mais próximas da população adscrita. Isso ocorre com o intuito de facilitar a participação da população no CLS e levar ao conselho municipal discussões mais contextualizadas sobre a realidade municipal.

O que notamos, porém, é que uma série de dificuldades foi enfrentada para a efetivação desses conselhos. Dificuldades que tendem a desviar os caminhos desejados da participação social no âmbito do SUS, comprometendo enormemente a efetivação desses espaços no município.

O sentimento, por parte da população, de não pertencimento aos CLSs apareceu como uma das questões para o progresso do conselho. Tal se deu, principalmente, pelo fato de não se ter envolvido a comunidade no processo de criação dos conselhos. Outro fator que auxiliou nesse processo foi 
a grande rotatividade de moradores em comunidades surgidas em razão da implantação de multinacionais no município. Assim, se a população não se sente pertencente e acolhida no local em que vive, ela não luta por melhorias ou mudanças dele.

$\mathrm{Na}$ fala dos conselheiros entrevistados, mereceu destaque como grande dificuldade a falta de processo de formação específica. Eles não se sentiam apropriados de seu papel de conselheiros; desse modo, como conseguiriam se colocar como sujeitos políticos que resistem às relações de dominação, opressão e subordinação? Sujeitos que se articulam e criam formas de resistência, na busca por políticas públicas que transformem os antagonismos da ação política e assim radicalizem a democracia, com um governo realmente de todos, com todos?

Entendemos que uma das saídas importantes para sanar esse sentimento de falta de capacidade no exercício do papel de conselheiro se encontra na implementação de programas de educação permanente, com o propósito de discutir com os conselheiros como o conhecimento sobre o território que habitam é a principal ferramenta para o exercício do cargo de conselheiro.

Finalmente, parece-nos que a vontade política para a criação dos conselhos locais não basta para que se efetive sua institucionalização. A participação social e seus mecanismos instituídos devem surgir do desejo e do entendimento da população como meio importante para a manutenção e a construção da política de saúde. Percebemos, nesta pesquisa, que o entendimento dos gestores municipais e dos trabalhadores de que a constituição de CLSs é uma estratégia importante não basta para sua concretização. Quando a população de usuários dos serviços foi desconsiderada na elaboração das referidas instâncias, eles passaram a não se reconhecerem como pertencentes a esses espaços; afinal, não puderam opinar sobre como elas poderiam funcionar nem dizer se as achavam viáveis. Tal constatação reforça a importância da participação da população para a efetivação do trabalho dos CLSs. 


\section{Colaboradores}

Edgar Andrade Lisboa trabalhou na concepção, delineamento, análise e interpretação dos dados, e redação final do artigo. Francis Sodré contribuiu no delineamento, análise e interpretação do dados, redação final do artigo, revisão crítica e aprovação da versão a ser publicada. Maristela Dalbello Araújo cooperou no delineamento, redação final do artigo, revisão crítica e aprovação da versão a ser publicada. Bruna Ceruti Quintanilha participou do delineamento, redação final do artigo, revisão crítica e aprovação da versão a ser publicada. Sara Gonçalves Luiz colaborou na redação final do artigo, revisão crítica e aprovação da versão a ser publicada.

Resumen Este estudio analizó la creación y la implantación de los consejos locales de salud en el municipio de Anchieta, en el estado de Espírito Santo, Brasil. Se buscó identificar los factores que apoyaron o limitaron su participación efectiva en el contexto del Sistema Único de Salud local. Mediante un abordaje cualitativo, se realizaron 13 entrevistas con los consejeros. Se utilizó el análisis de contenido, destacando tres categorías trabajadas en este texto: ¿Ser o no ser consejero de salud? ¡Esa es la cuestión!; La no pertenencia y la no participación; y Consejos locales de salud: vínculos, medios y mediaciones. Se concluyó que los consejeros enfrentan grandes dificultades que terminan desvirtuando los caminos deseados de la participación social en el ámbito del Sistema Único de Salud. Por eso, es imprescindible que haya voluntad política, apoyo a la participación efectiva y programas de educación para la ciudadanía de los actores involucrados en esos foros, para que puedan así ejercer su papel en forma plena.

Palabras clave Sistema Único de Salud; participación social; consejos de salud.

\section{Notas}

1 Universidade Federal do Espírito Santo, Programa de Pós-Graduação em Saúde Coletiva, Vitória, Espírito Santo, Brasil.

<edgarsax_17@yahoo.com.br>

Correspondência: Rua Herman Stern, 235, Condomínio Recreio das Palmeiras, bloco F, apartamento 608, Colina de Laranjeiras, CEP 29167-081, Serra, Espírito Santo, Brasil.

2 Universidade Federal do Espírito Santo, Centro de Ciências Jurídicas e Econômicas, Departamento de Serviço Social, Vitória, Espírito Santo, Brasil.

$<$ francisodre@uol.com.br>

3 Universidade Federal do Espírito Santo, Programa de Pós-Graduação em Saúde Coletiva, Vitória, Espírito Santo, Brasil.

$<$ dalbello.araujo@gmail.com> 
4 Universidade Federal do Espírito Santo, Programa de Pós-Graduação em Psicologia, Vitória, Espírito Santo, Brasil.

<quintanilhabc@gmail.com>

5 Universidade Federal do Espírito Santo, Programa de Pós-Graduação em Saúde Coletiva, Vitória, Espírito Santo, Brasil.

<saragluiz@gmail.com>

6 Alguns empreendimentos a serem desenvolvidos na região e especificamente em Anchieta: Porto da Petrobrás, Ferrovia Litorânea, quarta usina Samarco e siderúrgica CSU, da Vale. Estes gerariam impactos econômicos a partir da geração de emprego e renda e aumento considerável das receitas do município, arrecadação de impostos e da participação dos royalties do petróleo.

\section{Referências}

ANCHIETA (Município). Lei n. 628, de 3 de agosto de 2010. Disponível em: <https:// leismunicipais.com.br/a/es/a/anchieta/ lei-ordinaria/2010/62/628/lei-ordinaria-n628-2010-cria-os-conselhos-locais-desaude-2010-08-03.html>. Acesso em: 5 jul. 2016.

BARDIN, Laurence. Análise de conteúdo. Lisboa: Edições 70, 2000.

BISPO JÚNIOR, José P.; MARTINS, Poliana C. Envolvimento comunitário na Estratégia Saúde da Família: dilemas entre institucionalização e efetiva participação. Physis: Revista de Saúde Coletiva, Rio de Janeiro, v. 22, n. 4, p. 1.313-1.332, 2012.

BRASIL. Ministério da Saúde. Secretaria de Gestão Estratégica e Participativa. Departamento de Apoio à Gestão Participativa. Participação social em saúde. Brasília: Ministério da Saúde, 2006.

BRASIL. Portaria GM/MS n. 1.996, de 20 de agosto de 2007. Dispõe sobre as diretrizes para a implementação da Política Nacional de Educação Permanente e dá outras providências. Diário Oficial da União, Poder Executivo, Brasília, DF, 21 ago. 2007. Seção I. p. 34. Disponível em: <www.jusbrasil.com. br/diarios/686866/pg-34-secao-1-diariooficial-da-uniao-dou-de-22-08-2007>. Acesso em: 5 jul. 2016.

BRASIL. Instituto Brasileiro de Geografia e Estatística (IBGE). Censo demográfico 2010. Disponível em: <www.censo2010.ibge.gov. br>. Acesso em: 5 jul. 2016.

BRASIL. Resolução n. 466, de 12 de dezembro de 2012. Diretrizes e Normas Regulamentadoras de Pesquisas Envolvendo Seres Humanos. Diário Oficial da União, Poder Executivo, Brasília, DF, 12 dez. 2012. Seção I. p. 59. Disponível em: <www.jusbrasil.com. br/diarios/55483111/dou-secao-1-13-062013-pg-59> Acesso em: 05 jul. 2016.

BRAVO, Maria I. S. Gestão democrática na saúde: o potencial dos conselhos. In: BRAVO, Maria I. S.; PEREIRA, Potyara A. P. (orgs.). Política social e democracia. São Paulo: Cortez; Rio de Janeiro: Eduerj, 2001.

CARMO, João. Anchieta/ES conquista prêmio nacional de gestão participativa na saúde [Internet]. Anchieta, 2012. Disponível em: $<$ www.redemunicipiosps.org.br/wordpress/ $? p=1518>$. Acesso em: 20 set. 2013. 
CORREA, Maria V. C. Que controle social? Os conselhos de saúde como instrumento. Rio de Janeiro: Editora Fiocruz, 2000.

CÔRTES, Soraya M. V. Conselhos e conferências de saúde: papel institucional e mudança nas relações entre Estado e sociedade. In: FLEURY, Sonia; LOBATO, Lenaura V. C. (orgs.). Participação, democracia e saúde. Rio de Janeiro: Cebes, 2010. p. 102-128.

COTTA, Rosângela M. M. et al. O controle social em cena: refletindo sobre a participação popular no contexto dos conselhos de saúde. Physis: Revista de Saúde Coletiva, Rio de Janeiro, v. 21, n. 3, p. 1.121-1.138, 2011.

CRUZ, Pedro J. S. C. et al. Desafios para a participação popular em saúde: reflexões a partir da educação popular na construção de conselho local de saúde em comunidades de João Pessoa, PB. Saúde e Sociedade, São Paulo, v. 21, n. 4, p. 1.087-1.100, 2012.

DEMO, Pedro. Cidadania tutelada e cidadania assistida. Campinas: Autores Associados, 1995.

FARIAS, Jairo L. C. A dicotomia entre democracia representativa e democracia participativa e a educação no Brasil. Sociedade em Debate, Pelotas, v. 17, n. 2, p. 69-88, jan./jun. 2011.

FERREIRA, Fayer F. Implantação dos conselhos locais em Anchieta: mudanças. Web Artigos. Disponível em: <www.webartigos. com/_resources/files/_modules/article/ article_93796_20120810081445d9b0.pdf > . Acesso em: 2 jul. 2012

FLICK, Uwe. Entrevistas semiestruturadas. In: FLICK, Uwe. Uma introdução à pesquisa qualitativa. 2. ed. Porto Alegre: Bookman, 2004. p. 106-110.

GASKELL, George. Entrevistas individuais e de grupos. In: BAUER, Martin W.; GASKELL, George (orgs.). Pesquisa qualitativa com texto, imagem e som: um manual prático. Petrópolis: Vozes, 2002. p. 64-89.
GUIZARDI, Francini L. Do controle social à gestão participativa: interrogações sobre a participação política no SUS. Trabalho e Educação em Saúde, Rio de Janeiro, v. 7, n. 1, p. 9-34, 2009.

GUIZARDI, Francini L.; PINHEIRO, Roseni. Dilemas culturais, sociais e políticos da participação dos movimentos sociais nos conselhos de saúde. Ciência \& Saúde Coletiva, Rio de Janeiro, v. 11, n. 3, p. 797-805, 2006.

INSTITUTO FUTURA. Agenda 21 de Anchieta: documento de referência. Relatório da Agenda 21. Anchieta: Instituto Futura, 2005. p. 41, 47-50, 59.

JACOBI, Pedro R. Políticas sociais locais e os desafios da participação citadina. Ciência \& Saúde Coletiva, Rio de Janeiro, v. 7, n. 3, p. 443-454, 2002.

LISBOA, Edgar A. Conselhos locais de saúde: caminhos e (des)caminhos da participação social no Sistema Único de Saúde. 101 fls. Dissertação (Mestrado em Saúde Coletiva) Programa de Pós-Graduação em Saúde Coletiva, Universidade Federal do Espírito Santo, Vitória, 2014.

LONGHI, Jean C.; CANTON, Giselle A. M. Reflexões sobre cidadania e os entraves para a participação popular no SUS. Physis: Revista de Saúde Coletiva, Rio de Janeiro, v. 21, n. 1, p. 15-30, 2011 .

LUIZ, Sara G.; QUINTANILHA, Bruna C.; DALBELLO-ARAÚJO, Maristela. Educação permanente para conselheiros de saúde do município de Vitória. Universo da Psicologia, Nova Venécia, v. 2, n. 2, p. 25-37, 2014.

LYRA, Rubens P. Democracia representativa $\mathrm{x}$ democracia participativa: a representação do estado e da sociedade civil nos conselhos de políticas públicas. In: SEMINÁRIO NACIONAL SOBRE MOVIMENTOS SOCIAIS, PARTICIPAÇÃO E DEMOCRACIA, 2, Florianópolis, 25-27 abr. 2007. Anais... Florianópolis: Núcleo de Pesquisa em Movimentos Sociais, Universidade Federal de Santa Catarina, 2007. Disponível em: <www. 
dhnet.org.br/direitos/militantes/rubenspinto/ rubens_democracia_representativa_ participativa.pdf>. Acesso em: 5 jul. 2016.

MARTINS, Poliana C. et al. Conselhos de saúde e a participação social no Brasil: matizes da utopia. Physis: Revista de Saúde Coletiva, Rio de Janeiro, v. 18, n. 1, p. 105-121, 2008.

MARTINS, Poliana C. et al. De quem é o SUS? Sobre as representações sociais dos usuários do Programa Saúde da Família. Ciência \& Saúde Coletiva, Rio de Janeiro, v. 16, n. 3, p. 1.933-1.942, 2011.

MINAYO, Maria C. S. Trabalho de campo: contexto de observação, interação e descoberta. In: MINAYO, Maria C. S. (org.). Pesquisa social: teoria, método e criatividade. 26. ed. Petrópolis: Vozes, 2007. p. 64.

MINAYO, Maria C. S. O desafio do conhecimento: pesquisa qualitativa em saúde. 11. ed. São Paulo, Rio de Janeiro: Hucitec, Abrasco, 2008.

MOREIRA, Roberto J. Identidades complexas no conhecimento científico sobre comunidades costeiras. In: AMODEO, Nora B. P.; ALIMONDA, Hector (orgs.). Ruralidades, capacitação e desenvolvimento. Viçosa: Ed. UFV, 2006. p. 177-200.

RAMOS, Michelle F. et al. Conselhos setoriais: perfil dos conselheiros e sua influência na tomada de decisão. Saúde e Sociedade, São Paulo, v. 21, supl. 3, p. 61-70, dez. 2012. Disponível em: $<$ www.scielo.br/scielo.php?script= sci_arttext\&pid=S0104-12902012000700006>. Acesso em: 5 jul. 2016.
RAUTA MARTINS, Leonardo; RAUTA RAMOS, Maria H. Territórios em disputa: a instalação de grandes projetos e sua relação com a comunidade local. In: ENCONTRO NACIONAL DE GEOGRAFIA AGRÁRIA, 21, Uberlândia, 15-19 out. 2012. Disponível em: <www. lagea.ig.ufu.br/xxlenga/anais_enga_2012/ eixos/1089_1.pdf>. Acesso em: 15 set. 2013.

SIMIONI, Ana M. C.; LEFÈVRE, Fernando; BICUDO PEREIRA, Isabel M. T. Metodologia qualitativa nas pesquisas em saúde coletiva: considerações teóricas e instrumentais. São Paulo: Faculdade de Saúde Pública da Universidade de São Paulo, Departamento de Prática de Saúde Pública, 1997. (Série Monográfica, 2).

SORATTO, Jacks; WITT, Regina R.; FARIA, Eliana M. Participação popular e controle social em saúde: desafios da Estratégia Saúde da Família. Physis: Revista de Saúde Coletiva, Rio de Janeiro, v. 20, n. 4, p. 1.227-1.243, 2010

TOMAZELLI, Rondinelli. Em Anchieta, o desafio do crescimento. A Gazeta (on line), Vitória, 26 jul. 2012. Disponível em: <http:// gazetaonline.globo.com/_conteudo/2012/ 07/noticias/a_gazeta/politica/1324525-emanchieta-o-desafio-do-crescimento.html>. Acesso em: 30 set. 2013.

VIANNA, Maria L. T. W.; CAVALCANTI, Maria L.; CABRAL, Marta P. Participação em saúde: do que estamos falando? Sociologias, Porto Alegre, v. 11, n. 21, p. 218-251, 2009.

Recebido em 27/08/2014

Aprovado em 23/06/2015 